This item was submitted to Loughborough's Research Repository by the author.

Items in Figshare are protected by copyright, with all rights reserved, unless otherwise indicated.

\title{
Children's perspectives on their economic activity—Diversity, motivations and parental awareness
}

\author{
PLEASE CITE THE PUBLISHED VERSION
}

https://doi.org/10.1111/chso.12377

\section{PUBLISHER}

Wiley

\section{VERSION}

AM (Accepted Manuscript)

\section{PUBLISHER STATEMENT}

This is the peer reviewed version of the following article: XOLOCOTZIN, U. and JAY, T., 2020. Children's perspectives on their economic activity-Diversity, motivations and parental awareness. Children \& Society, 34 (5), pp.424-442, which has been published in final form at https://doi.org/10.1111/chso.12377. This article may be used for non-commercial purposes in accordance with Wiley Terms and Conditions for Use of SelfArchived Versions.

\section{LICENCE}

CC BY-NC-ND 4.0

\section{REPOSITORY RECORD}

Xolocotzin, Ulises, and Timothy Jay. 2020. "Children's Perspectives on Their Economic Activity—diversity, Motivations and Parental Awareness”. Loughborough University. https://hdl.handle.net/2134/13176371.v1. 


\begin{abstract}
This research investigates how children from an affluent city in the UK exercise agency to construct their economic worlds. A survey $(n=484)$ showed that children (ages 10 to 14 years) conduct a range of monetary and non-monetary activities. A second study $(n=83)$ with diaries, self-documentation, and parental questionnaires, showed that children's economic activity involves individual and social motivations, occurs in formal and informal contexts, and is often self-regulated. Parents acknowledge children's monetary activities and neglect non-monetary activities. The results suggest that children's agency unfolds in diverse economic activities shaped by contextual factors and interactions with peers and parents, thereby supporting a relational view of children's agency.
\end{abstract}

Keywords: economic activity, economic socialization, children's agency, childhood studies 


\section{Children's perspectives on their economic activity - Diversity, motivations, and parental awareness}

\section{Introduction}

Children's capacity to shape the social environment that shapes them is widely recognised. However, it is necessary to recognize that agency is not an essential characteristic of children that does not require further explanation (Prout, 2004; Oswell, 2013; Abebe, 2019; Sutterlüty and Tisdall, 2019). Children shape their social world in different ways, depending on the context (Wyness, 2018). Therefore, it is necessary to explain how agency operates in practical situations (Hutchby and Moran-Ellis, 2005; Oswell, 2013). There is space in the literature for more studies that explore children's economic agency within a variety of social relationships, e.g., family (Haugen, 2010) and peers (Konstantoni, 2012), and institutions, e.g., schools (Markström and Halldén, 2009; Kirby, 2019). The current research adds to this literature with an account of children's agency in the context of their economic activity.

Contemporary perspectives on childhood consider that agency is not an individual attribute, but something that individuals construct through their relationships with other people (Wyness, 2018; Sutterlüty and Tisdall, 2019). This research instantiates this relational notion of agency by investigating how children relate to peers and adults to construct economic activities in formal institutions, such as banks and shopping centres, and informal settings such as the house or the school. The research was conducted in a city in the UK. 


\section{Previous studies about children's economic agency}

Previous studies have investigated the economic agency exercised by working children from the global south (e.g., Libório and Ungar, 2010) and financially struggling children from the global north (Ridge, 2011). In comparison, less is known about the economic agency of children from middle-income households. The economic activity of children has been studied from an economic socialization perspective, covering themes such as money management (Lunt and Furnham, 1996; Furnham, 1999b, 1999a, 2001; Ashby, Schoon and Webley, 2011), patterns of consumption (Chaplin and John, 2007), and understanding of financial concepts (Leiser and Beth Halachmi, 2006; Halik and Webley, 2011). This literature needs to be complemented with studies that document children's active participation in the construction of their economic worlds (e.g., Levison, 2000; Cook, 2001; Zelizer, 2002; Stolp, 2011).

The study of formal activities is necessary but insufficient to understand children's economic agency. Webley and Lea (1993) argued that adult-centred views are unrealistic because children construct economic activities that are inconsistent with the adult notion of "economic". For children, the term "economic" is more than a label for behaviours such as working, spending, borrowing or lending money, and also applies to activities that they can control. For example, children define the relative value of the goods to make economic decisions in swapping practices.

The current study used a comprehensive notion of economic activity that included formal monetary activities, and activities involving non-monetary goods in scenarios such as the house, the school, or the streets (Webley, 1996; Nukaga, 2008; Mclntosh and Punch, 2009). Although primarily economic, these types of activity are 
ostensibly different (Webley and Lea, 1993). Therefore, we explored whether children's agency expressed differently in monetary and non-monetary activities. Below we present a review of the literature covering these activities.

\section{Monetary activity}

Parents are expected to oversee children's economic socialization. In the global north, most parents provide pocket money to ensure that their children are financially literate and responsible (Furnham and Milner, 2017; Sansone, Rossi and Fornero, 2019). Parents also intend to control how children use money, for example, by saving money on behalf of their children to promote saving habits (Friedline, 2012) and discussing financial issues with them (Kim, LaTaillade and Kim, 2011). However, children's financial practices are not entirely controlled by parents.

Survey studies suggest that children save money regardless of whether their parents promote financial habits (Webley and Nyhus, 2006; Ashby, Schoon and Webley, 2011). Furnham (1999b) found that children save because they want to achieve personal goals, e.g. to buy something special, rather than by parental encouragement. This research also showed that most children prefer moneyboxes under their control than saving accounts administered by parents.

Children and young people have potentially enormous spending power and, therefore, their consuming behaviours receive much attention (Shim, Serido and Barber, 2011). One key finding is that they spend money with little regard to adults' opinions (Shim, Serido and Barber, 2011). The purchase preferences of young people follow the 
expectations of peers (Shim, 1996), rather than the advice of adults (Bristol and Mangleburg, 2005).

Working children are a paradigmatic example of children's economic agency (Libório and Ungar, 2010). Current international policies on child labour aim to protect children from harmful work. However, assessing whether work is beneficial or detrimental to children requires considering not only the risks, but also its potential economic, educational, and social benefits (Bourdillon and Carothers, 2019). In the case of affluent societies such as the UK, paid employment is thought to promote responsibility and independence (Mizen, Bolton and Pole, 1999), and this can include giving money to children for doing domestic chores (Furnham, 1999a). However, the intention to earn money does not need to be directly encouraged by parents. For example, Stolp (2011) described how a group of pre-schoolers talked spontaneously about monetizing their school play.

\section{Non-monetary activity}

Direct access to money is limited for many children in affluent societies. However, their economic worlds are rich in activities that involve other forms of value. Children construct relationships with others through non-monetary activities, which illustrates the relational nature of children's agency. For example, swapping, sharing, exchanging and giving gifts, are an essential part of the interaction with siblings at home and with friends at school (Hay et al., 1999). For example, children may be more willing to share with their siblings at home than with their friends in the school, and more with their friends than with strangers (Markovits, Benenson and Kramer, 2003). 
Children express agency in establishing norms to rule their non-monetary activities. Mclntosh and Punch (2009) observed negotiations between siblings that involved idiosyncratic equivalences between goods (e.g., sweets, cards), labour (e.g., chores); and resources such as time and space. Webley and Lea (1993) documented a "marble economy" in which one child provided the marbles as capital and another child with more playing expertise provided the labour. This is similar to an adult model but has distinctive features. Adults would negotiate a balanced split of the profit (Bailey et al., 2015); but amongst these children, the capitalist always took much more marbles than the worker, regardless of the profit size.

Sometimes children construct activities that subvert the norms of adults. For example, Nukaga (2008) studied children exchanging food in an American school playground. The relational nature of children's agency was evident because children tailored the exchange rules to the multicultural composition of their school. Children of similar ethnicity shared but traded with those from different ethnicities.

Children also negotiate and transfer value when giving gifts. Children influence their parents to get the presents and birthday parties that they want (Clarke, 2007), and establish norms determined by the relationship between giver and receiver to define the kind of gift that is ought to be given or asked for (Sirota, 1998). Collecting is another activity that illustrates agency. Cook (2001) described that the collection of trading cards and toys involves economic processes, like weighting of value, and exchange rules. This author noticed how children's collecting practices combined their conventions with rules derived from the economy of adults, because the growing competition in card acquisition is often a consequence of planned scarcity (Cook, 2001). 


\section{Overview of this research}

The literature reviewed above shows that children actively construct diverse economic activities with their peers and parents. However, our understanding of such construction is partial and fragmented. To the extent of our knowledge, the current study is the first one to analyse an ample range of monetary and non-monetary economic activities. The participants represented a range of socioeconomic backgrounds, and some could have been economically vulnerable. The study took place in one of the most affluent cities in England, shortly after the implementation of austerity policies that made a substantial impact on the lives of children, especially amongst those living in low-income households (Ridge, 2013).

The current study involved children and young people aged $10-15$ because at these ages most children have developed critical capacities required to engage with economic activities, such as evaluation, patience, anticipation, and understanding of the role of others (Otto and Serido, 2017). Moreover, it is during this period that children start making more social relationships with peers and adults other than their close relatives. This expanding social environment brings about a range of activities that require transactions with resources and goods.

The method triangulated techniques to study the breadth and depth of children's economic activity. First, we surveyed the activities that constitute children's economic worlds. The survey findings guided the design of a subsequent study that involved diaries, self-documentation cards, and parental questionnaires. The research addressed the following research questions: 
RQ1 What is the scope of children's economic activity?

RQ2 Why, where, and how do children construct their economic activity?

RQ3 Are parents aware of their children's economic activity?

\section{Preliminary survey}

We conducted a survey that updates studies conducted about 20 years ago (Lunt and Furnham, 1996; Furnham, 1999b). The sample was taken from 6 schools across diverse sociodemographic areas in South West England. The percentages of children entitled to free school meals $(F S M)$ in each school ranged from 8 to 48 (Median $=23.5$ ). In total, 579 students answered the survey. 95 students were excluded from further analysis because they had more than $80 \%$ of missing responses, leaving a sample of 484 individuals (248 girls) enrolled in Year $5(n=122, M=10.06$ years), Year $7(n=182$, $M=12.43$ years $)$ and Year $9(n=180$, Mean $=14.21$ years $)$.

The ethics committee at the School of Education, University of Bristol, reviewed the methods and contents of the survey. Then, the authors contacted the authorities in each school to present the objectives of the survey and invite them to participate. Once the invitation was accepted, informed consent was requested from parents, who received an opt-out form and a letter outlining that children's participation in the study was voluntary, confidential and anonymous. Children were also informed of these conditions in the classroom. The surveys were answered in sessions of approximately 30 mins, in paper-and-pencil or electronically depending on the requirements of the school. Responses to the survey were captured electronically, anonymised, and stored in a secure server in the University of Bristol. 
The survey asked children about their favourite possessions, pocket money practices, and their monetary and non-monetary activity. Children ranked technology (e.g., mp3 players), gaming items (e.g., consoles, games) and mobile phones amongst their most favourite possessions. As for monetary activities, children reported getting $£ 8.27(S D=9.08)$ per week, mostly in the form of pocket money from their parents. Sizeable portions of children reported activities such as saving (70\%), borrowing (60\%), doing chores to earn money (65\%), spending money (44\%), and selling (33.9\%). Children reported several non-monetary activities, including giving gifts $(78.9 \%)$, borrowing things (51.4\%), swapping (44.8\%), and collecting (30.6\%).

ANCOVAs including the factors Year and Gender, and a covariate that served as a proxy of socioeconomic level, namely the percentage of children enrolled in the free school meal scheme of each school (FSM\%), were used to analyse aggregated variables indexing children's spending money, monetary activity, and non-monetary activity. Ethnicity was not included in the analysis because the data regarding this factor was not suitable to make informed conclusions about children's economic activity, i.e., about half of children described themselves as "white", and the rest defined themselves using a very ample range of diverse ethnicities. None of the included factors or the covariate influenced the aggregates of spending money and monetary activity. Nonmonetary activities were more frequent amongst girls, and Year 5 children reported more of these activities than children in Year 7 and Year 9.

The survey helped us to identify the most frequent activities amongst children and revealed that monetary and non-monetary activities involved different extents of adult participation. Although children undertook some monetary activities such as 
spending, selling and saving, without adult supervision, the money that they used mostly came from their parents (borrowed, or as earned or allowed pocket money), and they mainly transferred it to other adults (e.g., in selling). In contrast, adults had less participation in non-monetary activities than peers. These results guided the design of the self-documentation study presented below.

\section{Children's self-documentation of their economic activity}

Participants, materials, and procedure

This part of the research was carried out one year after the survey, including most of the same participants and others drawn from the same schools. The activities were discussed with teachers and school authorities, as well as with the ethics committee at the Graduate School of Education, University of Bristol. Parents and children gave informed consent to participate. Parents received an opt-out form and an information letter outlining the objectives of the study and clarifying that participation was voluntary, anonymous, confidential, and unrelated to the school activities. Children were also informed about these conditions in the classroom. We also considered other ethical issues more specific to the project. For example, parents decided what information about their income status to report, and agreements were made with schools to report situations in which children could be under risk.

This study focused on students from Year $6(n=46$, Mean age $=10.62$ years, 28 girls $)$ and Year $8(n=37$, Mean age $=12.36$ years, 18 girls $)$. It is expected that at these ages, children will tend to have reached a level of economic maturity and autonomy that would allow them to participate fully in the study (for a review, see Otto and Serido, 
2017). As far as the authors know, no special activities such as holidays or school events took place during the study that could have influenced the activities that children reported engaging with.

Data were collected over two weeks. In week 1 , children received a diary booklet for themselves and a questionnaire for their parents to complete. The questionnaire was for parents or carers to report about their child's monetary and non-monetary activities. In the booklets, children reported their economic activities by marking the ones they have done each day from Thursday to Sunday. The booklet showed a list of activities that, according to the preliminary survey, were more likely to take place. Monetary activities included receiving pocket money, saving at home, and various forms of spending and earning, e.g., doing chores for money or selling things. Non-monetary activities included collecting, giving gifts and various ways of transferring goods such as swapping and borrowing.

In week two children conducted a self-documentation activity. On Monday, children picked cards from two sets. One set included six cards with monetary activities: Working, Selling, Borrowing money, Lending money, Spending, and Saving. The other set included five cards with non-monetary activities: Borrowing things, Lending things, Giving gifts, Swapping things and Collecting. Children selected one 'monetary activity' card and one 'non-monetary activity' card with an activity they were likely to be taking part in the following week. Each card included four prompts or questions about the goods, persons, contexts, and ways of doing the activity, such as "who are you with when you do this?", "how do you decide how to do this activity?" "who helps you carry out this activity?". Children received a camera to take pictures of their activities. 


\section{Results}

\section{Diaries}

Here we report the percentages of children reporting each activity in the diary at least once. Multivariate analyses tested the effects of Gender and Year over aggregated variables indexing spending money, monetary activity, and non-monetary activity.

Spending money. More than half of the children reported spending money while going out with friends (63.7\%). Casual spending, e.g., in convenience stores or post offices, was reported by $43.4 \%$ and spending with parents by $38.6 \%$ of respondents. The added frequencies of spending money activities was processed with an ANOVA, which indicated no effects of Gender $[F(1,79)=2.74, n s]$, Year $[F(1,79)=0.37, n s]$, or their interaction $[\mathrm{F}(1,79)=0.08, n s]$.

Monetary activity. The most prevalent monetary activity was saving in a moneybox, reported by about half of children (57.8\%), followed by doing chores to get pocket money and borrowing or lending money, reported by about a third of children each $(31.3 \%$ and $28.9 \%)$. Only a few children reported selling $(15.7 \%)$ and having done a job outside the house (6\%). An ANOVA applied to the added frequencies of monetary activities revealed no effects of Gender $[F(1,79)=0.08, n s]$, Year $[F(1,79)=0.35, n s]$, or their interaction $[\mathrm{F}(1,79)=2.53, n s]$.

Non-monetary activity. Giving or receiving a gift and borrowing or lending things were the most prevalent of these activities, reported by around half of children each (57.8\% and $43.4 \%$ respectively). About a third reported swapping things $(32.5 \%)$ and about a quarter reported getting something to collect (24.1\%). The ANOVA applied to 
the added frequency of non-monetary activities revealed no effects of Gender $[F(1,79)$ $=2.16, n s]$, Year $[\mathrm{F}(1,79)=0.39, n s]$, or their interaction $[\mathrm{F}(1,79)<0.01, n s]$.

\section{Documentation cards}

Seventy children (41 from Year 6) returned 114 cards, 34 documented Spending money, 29 reported monetary activities (Saving, Selling, Working, Borrowing or lending money), and 51 reported non-monetary activities (Lending, Borrowing or Swapping, Collecting or Giving gifts). First, we processed the answers given to the prompts and questions in the cards. Out of the 493 answers collected, 452 were suitable for analysis. We discarded the rest because the writing was unreadable or the content was too ambiguous, e.g., Where do you save money? Yes.

We classified the answers in categories nested within three overarching themes: Motivation, context, and regulation. This scheme was defined to identify the orientation of children's activities and their ways of going about them. Two independent researchers applied the coding scheme to classify the answers in $33.6 \%$ of the cards; the interrater analysis revealed good reliability $($ Kappa $=.702, p<.001)$.

Motivation. Broadly defined as the kind of goal with which individuals seemed to pursue their activities. The initial exploratory analysis suggested that an individualistic vs social approach seemed appropriate to characterize children's motivations. Therefore, we classified children's motivations in the following categories:

- Individual. Answers mentioning the acquisition of goods for individual enjoyment or reward, or answers suggesting that the goods or benefits obtained with the activity do not benefit others and are not to be shared or used in a collective activity, 
including answers in which there is no mention of other individuals directly related to the activity. For example:

What do you like buying? Sweets and toys

Do you know anyone who collects what you collect? No

- Social. Answers indicating that children carried out the activity to benefit others, or that they used or shared with others the outcomes of the activity. For example:

What do you do with the things you collect? I trade them

Why do you lend? Because they need it

- Unspecified. Instances of this category indicate that goods or money are used or accumulated, but no specific reason to do it is given. For example:

What do you do with the money you are paid? I spend it

Context. This theme characterized the location in which children's activity took place. Since we wanted to explore if children carried out their activities outside formal economic institutions, we used two categories:

- Informal. The activity occurred at a place that is not an economic institution in the formal sense, such as the school, children's own home, or someone else's home. For example:

Where do you lend things? At home with my friends

- Formal. The activity occurs in formal economic institutions, such as shops, banks or places with a formal economic structure such as car-boot sales. For example:

Where do you save your money? In a post office account 
Regulation. We were interested in the extent of what children self-govern their economic activity. Therefore, the categories in this theme indicate whether adults or peers regulated children or if children used self-regulation strategies. There were three categories:

- Self-regulation. The answer mentions at least one regulatory action that the individual performs, without mentioning help or advice from parents, friends or other people. These could be simple actions such as looking at the tags when shopping or more sophisticated ones such as writing down how much money is spent. For example:

How do you know what is worth collecting? By the price, and I know someone who is collecting them

- Guidance. The answer makes explicit reference to the help or advice from parents or friends to carry out the activity. For example:

Who helps you to spend money? My parents

- Unspecified. The activity is carried with no apparent self-regulation or guidance from others, denoting a way of doing things which structure cannot be identified. For example:

How do you know what is worth collecting? I do not know

We analysed the themes concerning each type of activity. A dichotomous dependent variable indexed whether an individual had at least one answer classified in a category. Fig 1.34 summarizes the data, 34 children returned at least one card documenting spending money, 33 documented at least one monetary activity, and 52 
documented at least one non-monetary activity. Children often responded to the questions in the cards with more than one answer, and these answers could be classified into different categories within the same theme. Because children could respond to more than one category, we used Cochran's $Q$ tests to explore the data, followed by McNemmar pairwise comparisons.

Fig. 1 about here

Spending money. There was a main effect of motivation $\left(\chi^{2}=58.24, p<.001\right)$. Children reported more individual motivations than social and nonspecified ones, while social and nonspecified motivations were equally unlikely. The main effect of context was also significant. As expected, children were more likely to spend money in formal economic contexts $\left(\chi^{2}=17.63, p<.001\right)$. There was a main effect of regulation $\left(\chi^{2}=34\right.$. $47, p<.001)$. Children were equally likely to spend money using self-regulation strategies or following someone's assistance, and both forms of regulation were more likely than nonspecified ones.

Monetary activity There was a main effect of motivation $\left(\chi^{2}=12.19, p<.005\right)$. Individual and unspecified motivations were more frequent than social ones, whereas individual and nonspecified were equally likely. As for context, monetary activities were more likely to occur in informal contexts $\left(\chi^{2}=12.89, p<.001\right)$. There was a main effect of regulation $\left(\chi^{2}=30.78, p<.001\right)$. Self-regulation strategies were more likely than 
following someone's guidance, and both were more frequent than nonspecific forms of regulation.

Non-monetary activity There was a main effect of motivation $\left(\chi^{2}=14.29, p\right.$ $<.005)$. Individual and social motivations were equally likely, and both were more frequent than nonspecified ones. The analysis of context revealed that non-monetary activities were more likely to occur in informal contexts $\left(\chi^{2}=21.33, p<.001\right)$. There was a main effect of regulation $\left(\chi^{2}=56.97, p<.001\right)$. Self-regulation strategies were more likely than following guidance, whereas guidance and nonspecified forms of regulation were equally unlikely.

\section{Agreement between children's diaries and the questionnaire for}

\section{parents}

We assessed the agreement between the responses given by children in the diaries and what their parents answered in the questionnaire for parents. All the participants returned the questionnaire, but 21 had more than $80 \%$ missing data and were discarded, leaving 62 for analysis. Cohen's Kappa at the dyad level indexed the agreement between children and parents. First, we assessed the child-parent agreement with a nominal dyad technique (Kenny, Kashy and Cook, 2006). Kappas of actual dyads were compared with Kappas of nominal dyads, that consisted of children and parents paired randomly post-hoc, controlling for year and gender. The reference nominal value was the median of nominal Kappas across five iterations. Kappas of actual child-parent dyads were higher than nominal kappas in monetary activities, $t$ (61) $=2.32, \mathrm{p}<.05$, but not in non-monetary ones $t(61)=0.19$, ns, which indicates that 
parental views of children's monetary activity tend to be accurate, whereas their views on non-monetary activity and their children's accounts were inaccurate.

Further analysis of child-parent kappas consisted of a mixed ANOVA, including the within-participants factor Activity (monetary/non-monetary), and the betweenparticipants factors Year (6/8) and Gender (female/male). A main effect of activity indicated that a parent's reports agreed more with his or her child's report concerning monetary activities than concerning non-monetary ones $\left[\mathrm{F}(1,58)=5.101, p<.01, \eta_{p}^{2}\right.$ $=.28]$. A main effect of year indicated that Year 8 parents agreed more with their children than Year 6 parents $\left[F(1,58)=23.11, p<.05, \eta_{p}^{2}=.08\right]$. The main effects of gender and the gender $x$ year interaction were not significant (see Figure 2).

Figure 2 about here

\section{Discussion}

This work contributes to understanding how children in an affluent city exercise their economic agency. We used a notion of economic activity that included activities aligned with the formal economy and activities that might not be seen as economic from the perspective of adults but are nevertheless economic (Webley and Lea, 1993). To look at children's economic activities from their perspective, we used a large-scale survey and a methodology that triangulated diaries, documentation cards and questionnaires for parents. Below we discuss the findings concerning the research 
questions. Then we conclude outlining how these findings reflect the relational nature of children's economic agency.

\section{What is the scope of children's economic activity?}

The findings revealed that children construct economic worlds that are diverse and have limited influence from adults. The patterns of economic activity observed in the survey, and the diaries were reasonably similar, albeit with some inconsistencies. There were no effects of gender and year in the diaries data, whereas these effects were significant for the non-monetary activities in the survey. Maybe the effects of year in the diaries data were not significant because the sample was smaller than in the survey, or because the age difference between the participants were smaller in the diaries data than in the survey. As for gender, maybe the differences between boys and girls appear in later stages of development, and they were observed in the survey because participants were older than the participants in the diaries.

It is necessary to acknowledge that this research offers limited information about the effects of socioeconomic status on children's economic activity. The survey asked children about the occupation of their parents. However, their answers were very ambiguous, and it was difficult to classify the occupations of children's parents reliably. In the questionnaire for parents, we asked directly about the household income, but most parents were reluctant to answer this question. Consequently, we used the percentage of children in the FSM scheme of the participant schools as a proxy of SES at the level of schools. This measure did not correlate with the aggregated measures of economic activity. Maybe the effects of SES on a child's economic activity operate only at the level of individuals, but not at the level of schools. The extent to which children's 
SES influences their economic activity deserves a dedicated study, with a methodology capable of obtaining reliable information about this variable.

One expected result was that parents have much influence over children's acquisition and use of money. Pocket money was the children's primary source of money. Also, similar proportions of children reported that they do chores to get pocket money and are more likely to borrow or lend with parents than with peers. Other, more independent ways to get money, such as selling and working were also reported, albeit rarely.

Despite the financial dependence from parents, children are not passive actors when engaging with monetary activities. Both the survey and the diaries indicated that ways of spending money in which parents have little influence, such as spending with friends and buying things on their own, were more prevalent than the indirect spending through parents. Also, saving money in a moneybox was preferred over institutionalized ways of saving, i.e., in bank accounts supervised by parents.

The similar prevalence of monetary and non-monetary activities demonstrates that children construct economic worlds on their own, composed by activities that involve the transference of goods that have little monetary costs, such as borrowing or lending things. Giving or receiving gifts and swapping were also reported, albeit with less frequency. In the same way as spending money, children likely carry out these nonmonetary activities following forms of self-regulation in which adults do not seem to be directly involved.

It is worth acknowledging that certain activities that are part of children's economic landscape were not covered in-depth by this research. The survey included 
follow-up and open-ended questions that asked about the contexts in which children carried out their economic activity. The proportions of children who reported spending or earning money on the internet were small $(\leq 15 \%)$, but some of the specific activities described were interesting, e.g., using online auctions websites. Similarly, very few students reported engaging in potentially subversive activities, such as the selling of sweets or mobile phone accessories in the school. Albeit infrequent, these kinds of activities are worth of systematic study in future research.

Why, where, and how do children construct their economic activity?

The documentation cards revealed insights about the motivations (why), contexts (where), and methods (how) of children's economic activities. Below we discuss how these qualities proved to be useful to characterize 12 monetary and non-monetary economic activities.

\section{Why? Understanding children's motivations}

Our approach to understanding the motivations driving children's economic activity consisted of looking at whether they pursued individual, social, or unspecified goals. Children described different goals depending on the sort of activity that they documented. Spending money was mainly driven by individual motivations (e.g., getting some food or clothes), and monetary activities (e.g., saving, borrowing or lending, working or selling) were motivated equally by individual motivations (e.g., lending money to borrow sweets), or by unspecified ones (e.g., saving 'just because'). In contrast, non-monetary activities involving the transference of goods (e.g., swapping, collecting, giving gifts) were motivated by both social and individual motivations. 
These findings are difficult to interpret with the mainstream conceptualization of economic activity, which is mainly concerned with activities that are consistent with formal economic models. What is lacking and much needed are frameworks that are capable of articulating this sort of activity with the activities that are inconsistent with the formal models, but that are also economic and relevant to children. Conventional conceptualizations of economic activity based on material utilitarianism may be limited. How can we explain that unspecified motivations drive monetary activities such as saving? It is unlikely that children save for no reason, so there may be unexplored forms of utility. Something similar occurs with the social motivations driving non-monetary activities such as swapping and exchanging. In this case, we need more studies to explain the nature of the social exchanges that might be involved in these activities.

Where? The importance of formal and informal economic contexts

There were also apparent differences across activities in terms of the context. Naturally, spending money occurred almost exclusively in formal economic contexts, e.g., shops, rather than in informal ones. However, an equally important part of children's economic activity occurs in informal contexts such as the house or the school. This includes activities such as selling, working and saving at home, as well as nonmonetary activities such as swapping, giving gifts or collecting. These contextual differences are evidence that we need to devise specific conceptual approaches to make sense of different types of economic activity. There might be apparent differences in the way in which formal and informal economic contexts frame children's behaviour. It is not difficult to imagine that the economic and social norms that guide children's 
behaviour when shopping for clothes in a store may be very different from the norms that rule the trade of collectible cards in the school.

How? The self-regulation of children's economic activity

The low rates of unspecified regulation indicated that children's economic activities involve organized actions. Moreover, self-regulation strategies were the most common form of regulation across the different types of activities, suggesting that children tend to act in self-regulated ways. In terms of spending money, this means that children can handle their own money systematically, e.g., keeping track of the amount to spend, although the data from the cards cannot tell us about the effectiveness of such strategies. For monetary and non-monetary activities, self-regulation implies a variety of ways to handle money and goods without direct guidance. Examples of this include counting the money saved on a moneybox or applying specialized knowledge to figure out the value of a collectible item.

Guided forms of regulation were also described, albeit with less frequency than self-regulation strategies, and only about spending money and monetary activities, which suggests that in terms of handling money, children operated under the influence of parents and other persons. This finding might be indicative of economic socialization processes in which adults guide children to assimilate and adopt financial habits that are necessary to be part of the formal economy.

\section{Are parents aware of their children's economic activity?}

The agreements and disagreements between the parental reports and what children reported illustrate a difference between monetary and non-monetary economic 
activities, in terms of children's level of agency. Parents tended to give accurate accounts of their children's monetary activities, which makes sense because, as the survey indicated, most of the children's money comes from their parents, and activities such as spending money involved more guidance from other persons, presumably the parents.

Parental awareness of non-monetary activities is mostly inaccurate, which is difficult to explain. It is unlikely that parents responded randomly to the questionnaires, but there may be various reasons for the mismatch. One can imagine that some parents do not know about specific activities that their children do because these are mostly carried out with friends (e.g., swapping, borrowing). It can also be the case that parents stereotype their children (e.g., assuming they ought to collect something).

Reasons apart, the mismatches between parents and children probably reflect that children's economic behaviour is equally shaped by the interiorization of household norms and by the social interactions that take place in contexts such as the school or the streets. This finding is innovative because so far, most research on economic behaviour has focused on parental socialization of monetary activities, leaving other forms of socialization and activities aside.

Another revealing result is that parents were more aware of the economic activities of older children. One plausible explanation is that parents disregard the economic agency of younger children. That is, parents might pay attention to activities that involve money while neglecting other forms of economic activity, in particular, those in which money is not a prominent component. Recall that younger children receive little 
amounts of money and that most of their monetary activity involves transactions with other adults (often parents).

The parental questionnaires helped us to understand how the way in which parents relate to their children might be part of children's economic worlds. The questionnaires are a methodological contribution, but we should consider that its use may have unintended consequences. Maybe the questionnaires opened discussions in which parents discovered that their children are more economically active than what they expect them to be. Future studies using this methodology might consider a followup interview to address situations like these.

\section{Acknowledging the relational nature of children's economic agency}

Our findings indicate that children from affluent contexts are also economic agents in their own right, just like children from economically disadvantaged societies and living in poverty. Overall, the results are consistent with contemporary voices that suggest a turn to the understanding of agency as something that individuals construct in relationships with people and structures (Wyness, 2018; Sutterlüty and Tisdall, 2019). We found that much of children's activity is carried out with peers, with little regulation from parents and outside formal economic institutions such as banks and shops. These qualities were also observed even in the ways that children interact with the formal economy by spending and using money. Even when parents exert much influence in the usage of money, children use their relationships with peers to transcend the boundaries of adult supervision, as is suggested by the prevalence of spending with friends and casual spending that they reported in the diaries. 
The relational nature of children's economic agency is explicit in non-monetary activities. Behaviours such as collecting, swapping, borrowing and lending things are more commonly carried out with peers, and only rarely with adults. Activities of this kind are likely to follow norms developed in the locality of kinships (Nukaga, 2008; Mclntosh and Punch, 2009) rather than the norms of formal economic models.

Our findings also suggest that children conduct with more self-regulation the activities that are not part of formal economic models. One explanation may be that children need less advice to understand and follow the norms that rule activities such as swapping, borrowing or collecting because they developed these norms in the locality of their relationships with their peers. In contrast, children inherit from adults the norms ruling the spending, production, and transference of money. Therefore, they need more adult guidance to undertake them. Another explanation is that non-monetary activities are more accessible than monetary ones. However, one should consider that transactions that may appear simple to the adults' eye, actually involve complex transactions of numerous norms, goods, and resources (Mclntosh and Punch, 2009).

\section{Concluding remarks}

There is much potential in looking at children's economic agency from their point of view, using a relational notion of agency. However, we are just starting to figure out what this means. The findings reported here indicate that we need more studies that investigate children's economic agency from their perspective. We also need to develop theoretical concepts to explain how children establish relations with peers, adults, and social structures to construct their economic activities. Future research should 
recognise the study of children's economic agency as an integral component of work to understand what it means for children to construct their social worlds actively.

\section{Acknowledgments}

The research reported in this article was funded by a grant from The Leverhulme Trust (grant number F/00 182/CL).

\section{References}

Abebe, T. (2019) 'Reconceptualising Children's Agency as Continuum and Interdependence', Social Sciences. doi: 10.3390/socsci8030081.

Ashby, J. S., Schoon, I. and Webley, P. (2011) 'Save Now, Save Later?', European Psychologist, 16(3), pp. 227-237. doi: 10.1027/1016-9040/a000067.

Bailey, P. E. et al. (2015) 'Trust and trustworthiness in young and older adults', Psychology and aging. American Psychological Association, 30(4), p. 977.

Bourdillon, M. and Carothers, R. (2019) 'Policy on Children’s Work and Labour', Children \& Society. John Wiley \& Sons, Ltd (10.1111), 33(4), pp. 387-395. doi: 10.1111/chso.12313.

Bristol, T. and Mangleburg, T. (2005) 'Not telling the whole story: Teen deception in purchasing', Journal of the Academy of Marketing Science. Springer Netherlands, 33(1), pp. 79-95. doi: 10.1177/0092070304269754.

Chaplin, L. N. and John, D. R. (2007) 'Growing up in a material world: Age differences in materialism in children and adolescents', Journal of Consumer Research. The University of Chicago Press, 34(4), pp. 480-493. Available at: http://www.jstor.org/stable/10.1086/518546. 
Clarke, A. J. (2007) 'Consuming children and making mothers: birthday parties, gifts and the pursuit of sameness', Horizontes antropológicos, 13, pp. 263-287.

Cook, D. T. (2001) ‘Exchange Value as Pedagogy in Children’s Leisure: Moral Panics in Children's Culture at Century's End', Leisure Sciences: An Interdisciplinary Journal, 23(2), pp. 81-98. Available at:

http://www.informaworld.com/10.1080/014904001300181684.

Friedline, T. (2012) 'Predicting children's savings: The role of parents' savings for transferring financial advantage and opportunities for financial inclusion', Children and Youth Services Review, 34(1), pp. 144-154. doi: 10.1016/j.childyouth.2011.09.010.

Furnham, A. (1999a) ‘Economic socialization: A study of adults perceptions and uses of allowances (pocket money) to educate children', British Journal of Developmental Psychology, 17, pp. 585-604. Available at:

http://www.ingentaconnect.com/content/bpsoc/bjdp/1999/00000017/00000004/art00008

Furnham, A. (1999b) 'The saving and spending habits of young people', Journal of Economic Psychology, 20(6), pp. 677-697. doi: 10.1016/S0167-4870(99)00030-6.

Furnham, A. (2001) 'Parental attitudes to pocket money/allowances for children', Journal of Economic Psychology, 22(3), pp. 397-422. Available at: http://www.sciencedirect.com/science/article/B6V8H-43B8CTS5/2/eac8441abe730933c835f6f63eec638b.

Furnham, A. and Milner, R. (2017) 'Parent's Beliefs and Behaviours about the Economic Socialisation, through Allowances/Pocket Money, of Their Children', 
Psychology. Scientific Research Publishing, 8(8), pp. 1216-1228.

Halik, M. and Webley, P. (2011) 'Adolescents' understanding of poverty and the poor in rural Malaysia', Journal of Economic Psychology, 32(2), pp. 231-239. doi: 10.1016/j.joep.2009.02.006.

Haugen, G. M. D. (2010) ‘Children’s Perspectives on Everyday Experiences of Shared Residence: Time, Emotions and Agency Dilemmas', Children \& Society. John Wiley \& Sons, Ltd (10.1111), 24(2), pp. 112-122. doi: 10.1111/j.10990860.2008.00198.x.

Hay, D. F. et al. (1999) 'Prosocial Action in Very Early Childhood', Journal of Child Psychology and Psychiatry. Blackwell Publishing Ltd., 40(6), pp. 905-916. doi: 10.1111/1469-7610.00508.

Hutchby, I. and Moran-Ellis, J. (2005) Children and social competence: Arenas of action. Routledge.

Kenny, D., Kashy, D. and Cook, W. (2006) Dyadic data analysis, Methodology in Social Sciences. Edited by D. A. Kenny. New York - London: Guilford Press.

Kim, J., LaTaillade, J. and Kim, H. (2011) 'Family Processes and Adolescents' Financial Behaviors', Journal of Family and Economic Issues. Springer Netherlands, 32(4), pp. 668-679. doi: 10.1007/s10834-011-9270-3.

Kirby, P. (2019) 'Children's Agency in the Modern Primary Classroom', Children \& Society. John Wiley \& Sons, Ltd (10.1111), 0(0). doi: 10.1111/chso.12357.

Konstantoni, K. (2012) 'Children's peer relationships and social identities: exploring cases of young children's agency and complex interdependencies from the Minority 
World', Children's Geographies. Routledge, 10(3), pp. 337-346. doi:

10.1080/14733285.2012.693382.

Leiser, D. and Beth Halachmi, R. (2006) 'Children's understanding of market forces', Journal of Economic Psychology, 27(1), pp. 6-19.

Levison, D. (2000) 'Children as Economic Agents', Feminist Economics. Routledge, 6(1), pp. 125-134. doi: 10.1080/135457000337732.

Libório, R. M. C. and Ungar, M. (2010) ‘Children’s Perspectives on their Economic Activity as a Pathway to Resilience', Children \& Society. John Wiley \& Sons, Ltd (10.1111), 24(4), pp. 326-338. doi: 10.1111/j.1099-0860.2009.00284.x.

Lunt, P. K. and Furnham, A. (1996) 'Economic socialization: the economic beliefs and behaviours of young people', in. Brookfield, Vt., US.

Markovits, H., Benenson, J. F. and Kramer, D. L. (2003) 'Children and Adolescents' Internal Models of Food-Sharing Behavior Include Complex Evaluations of Contextual Factors', Child Development. Blackwell Publishing, 74(6), pp. 1697-1708. doi: 10.1046/j.1467-8624.2003.00632.x.

Markström, A.-M. and Halldén, G. (2009) 'Children's Strategies for Agency in Preschool', Children \& Society. John Wiley \& Sons, Ltd (10.1111), 23(2), pp. 112-122. doi: 10.1111/j.1099-0860.2008.00161.x.

Mclntosh, I. and Punch, S. (2009) 'Barter', 'Deals', 'Bribes' and 'Threats”, Childhood, 16(1), pp. 49-65. doi: 10.1177/0907568208101690.

Mizen, P., Bolton, A. and Pole, C. (1999) 'School Age Workers: the Paid Employment of Children in Britain', Work, Employment \& Society, 13(3), pp. 423-438. doi: 
10.1177/09500179922118015.

Nukaga, M. (2008) 'The underlife of kids' school lunchtime', Journal of Contemporary Ethnography, 37(3), p. 342.

Oswell, D. (2013) The agency of children: From family to global human rights. Cambridge, UK: Cambridge University Press.

Otto, A. and Serido, J. (2017) 'Economic socialization: Childhood, adolescence, and early adulthood', in Ranyard, R. (ed.) Economic Psychology. (Wiley Online Books), pp. 319-336. doi: doi:10.1002/9781118926352.ch20.

Prout, A. (2004) The future of childhood. Routledge.

Ridge, T. (2011) 'The Everyday Costs of Poverty in Childhood: A Review of Qualitative Research Exploring the Lives and Experiences of Low-Income Children in the UK', Children \& Society. Blackwell Publishing Ltd, 25(1), pp. 73-84. Available at: http://dx.doi.org/10.1111/j.1099-0860.2010.00345.x.

Ridge, T. (2013) "We are All in This Together"? The Hidden Costs of Poverty, Recession and Austerity Policies on Britain's Poorest Children', Children \& Society. John Wiley \& Sons, Ltd (10.1111), 27(5), pp. 406-417. doi: 10.1111/chso.12055.

Sansone, D., Rossi, M. and Fornero, E. (2019) '"Four bright coins shining at me": Financial education in childhood, financial confidence in adulthood', Journal of Consumer Affairs. John Wiley \& Sons, Ltd (10.1111), 53(2), pp. 630-651. doi: 10.1111/joca.12207.

Shim, S. (1996) 'Adolescent consumer decision-making styles: The consumer socialization perspective', Psychology and Marketing. Wiley Subscription Services, Inc., 
A Wiley Company, 13(6), pp. 547-569. doi: 10.1002/(sici)1520-

6793(199609)13:6<547::aid-mar2>3.0.co;2-8.

Shim, S., Serido, J. and Barber, B. L. (2011) 'A Consumer Way of Thinking: Linking Consumer Socialization and Consumption Motivation Perspectives to Adolescent Development', Journal of Research on Adolescence, 21(1), pp. 290-299. doi: 10.1111/j.1532-7795.2010.00730.x.

Sirota, R. (1998) 'Les copains d'abord: Les anniversaires de l'enfance, donner et recevoir', Ethnologie française. Presses Universitaires de France, 28(4), pp. 457-471. Available at: http://www.jstor.org/stable/40990033.

Stolp, M. (2011) 'Children's art: Work or play? Preschoolers considering the economic questions of their theatre performance', Childhood. SAGE Publications, 19(2), pp. 251-265. doi: 10.1177/0907568211415556.

Sutterlüty, F. and Tisdall, E. K. M. (2019) 'Agency, autonomy and self-determination: Questioning key concepts of childhood studies', Global Studies of Childhood. SAGE Publications, 9(3), pp. 183-187. doi: 10.1177/2043610619860992.

Webley, P. (1996) 'Playing the market: the autonomous economic world of children', in Lunt, P. K. and Furnham, A. (eds) Economic Socialization. The Economic Beliefs and Behaviours of Young People. Cheltenham: Edward Elgar Publishing Limited, pp. 149161.

Webley, P. and Lea, S. E. G. (1993) 'Towards a more realistic psychology of economic socialization', Journal of Economic Psychology, 14(3), pp. 461-472.

Webley, P. and Nyhus, E. K. (2006) 'Parents' influence on children's future 
orientation and saving', Journal of Economic Psychology, 27(1), pp. 140-164. doi: 10.1016/j.joep.2005.06.016.

Wyness, M. G. (2018) 'The recognition and distribution of children's agency in the UK', in Dintner, S. and Schneider, R. (eds) Transdisciplinary Perspectives on Childhood in Contemporary Britain. Studies in Childhood: 1700 to the present. New York:

Routledge, pp. 250-271.

Zelizer, V. (2002) 'Kids and Commerce', Childhood, 9(4), pp. 375-396. Available at: http://chd.sagepub.com/content/9/4/375.abstract. 
Figure legends

Figure 1 Percentage of children classified within each category of motivation, context and regulation when documenting their spending money $(n=34)$ monetary activities $(n=33)$ and nonmonetary activities $(n=52)$.

Figure 2 Parent-children kappa by Year and type of Activity. The kappa statistics provide a measure of the agreement between parents and children; the chart shows the least agreement between parents and children's reports of activity when the focus is on Year 6 children's nonmonetary activity. 
Appendix 1. Sample pages from the booklet diaries

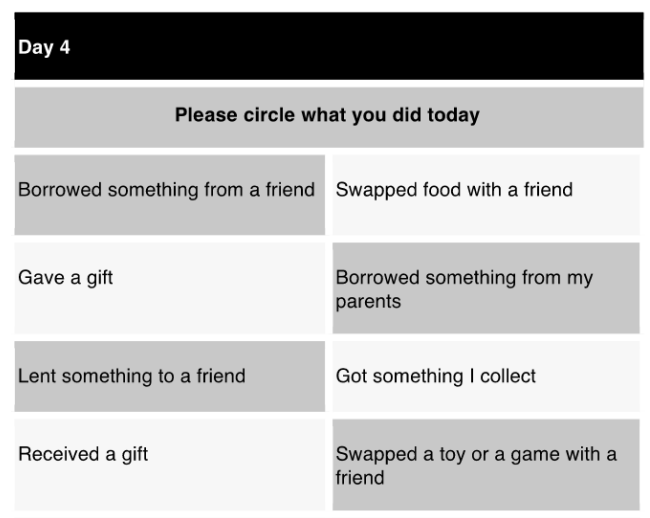

If you did something to get things without using money that is not listed here, what was it?

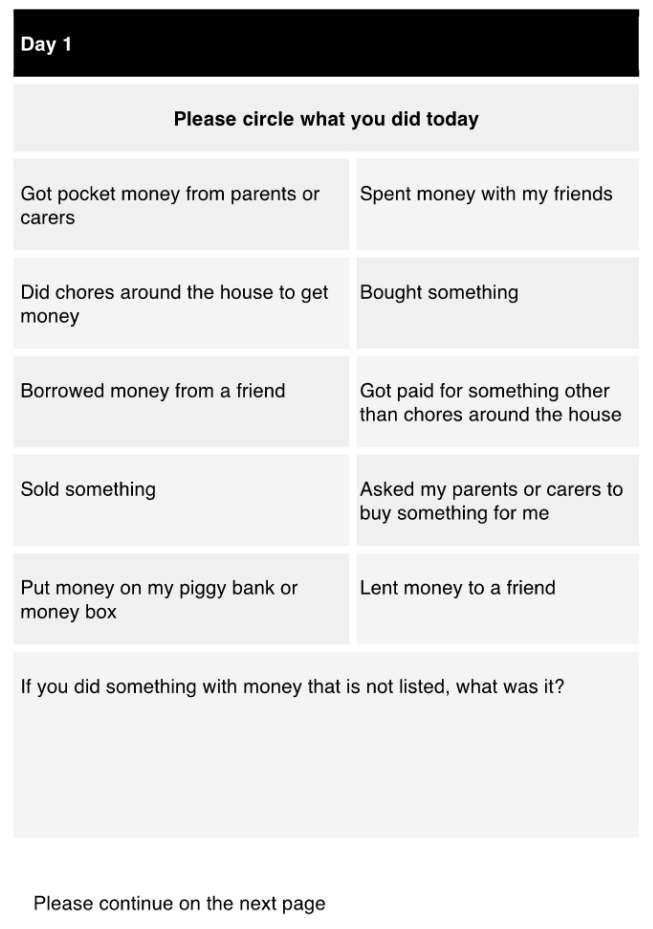


Appendix 2. Questions in the parent's questionnaires

Please answer or cross-out as appropriate

1. How often do you give pocket money to your child?

2. Does your child have to do anything to get pocket money?

3. Does your child get money in ways other than pocket money?

4. Do you recommend your child how to spend his or her pocket money?

5. How does your child spend her or his own money?

6. Do you encourage your child to save his or her money in a money box?

7. What are the three most valued possessions of your child, and why do you think he or she values them?

8. Do you know if your child collects anything?

9. Do you know if your child borrows things from his or her friends?

10. Does your child give gifts (e.g., at birthday parties?

11. Do you know if your child swaps things with her or his friends? 